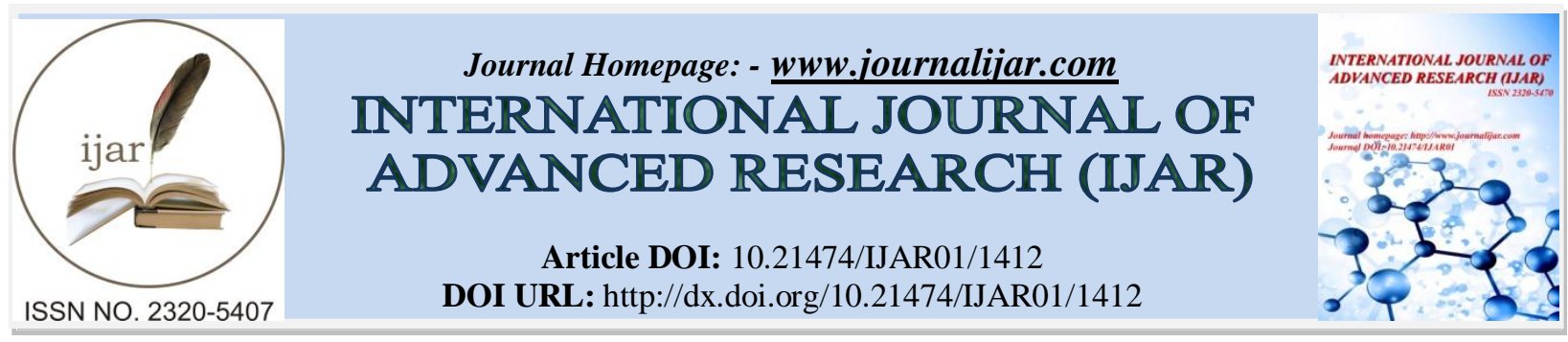

RESEARCH ARTICLE

\title{
FLUORIDE AND FOREST IN SOUTH-EAST DRY AGRO-CLIMATIC ZONES OF KARNATAKA USING REMOTE SENSING AND GIS TECHNIQUES.
}

Jagadeesha Menappa Kattimani* and T.J.Renuka Prasad. Department of Geology, Jnana Bharati Campus, Bangalore University, Bangalore-560056.

\section{Manuscript Info}

Manuscript History

Received: 12 June 2016

Final Accepted: 19 July 2016

Published: August 2016

Key words:-

Ground water, Fluoride, Chemical parameters, Agroclimatic zones

\section{Abstract}

Waterborne hydrofluorosis in both man and domestic animals has been widely studied almost in every state Most of the fluoride found in groundwater is naturally occurring from the breakdown of rocks and soils or weathering and deposition of atmospheric particles. The average value of Fluoride in the study area is $0.79 \mathrm{mg} / \mathrm{ltr}$. With a range of 0.01 to $3.90 \mathrm{ppm}$. Highest value showing in Northern-Eastern portion of Pavagada, Srinavasapura and Bagepalli taluks are shows high value of fluoride portion of the study area located in Chitradurga , In the forest region Fluoride ranges between Low $(0.01 \mathrm{mg} / \mathrm{ltr})$ to medium $(1.5 \mathrm{mg} / \mathrm{ltr})$ in the study area.

Copy Right, IJAR, 2016,. All rights reserved.

\section{Introduction:-}

Henceforth, water quality monitoring has been given the highest preference in health protection (World Health Organization 2006). With attaining the physico-chemical signature of ground water, hydro-geochemist unearth the possibilities of suitability of water for different purposes and study its chemical evolution processes. In other words, assessment of groundwater quality is needed to ensure its usability in different sectors in a safe manner (Vijith and Satheesh 2007). fluorine may be used to denote collectively the element in all its forms ionized or ionisable. Where, there is doubt as regards to ionizability, e.g., in certain foods, fluorine is actually the better, more comprehensive word (WHO 1970).

chronic fluoride poisoning is endemic in several states due to excess quantity of fluoride in drinking water sources, especially in the rural areas where this health problem is relatively more prevalent (Choubisa et al. 1995, 1996a, 2001; Choubisa 1997). Among the states in India, 50-100 \% districts are affected with fluoride intoxication in Andhra Pradesh, Gujarat, Rajasthan and Uttar Pradesh. While in Bihar, Haryana, Karnataka, Madhya Pradesh, Maharashtra, Punjab and Tamil Nadu and 30-50\% districts are endemic for fluoride intoxication (Choubisa 2012a).

\section{Location Map:-}

Location of the Study area:-

The study area is forest within the Dry Agro Climatic Region of Karnataka and spreads over in 3294 sqkm. It lies between $12^{\circ} 30^{\prime} 0^{\prime \prime}$ and $15^{\circ} 0^{\prime} 0^{\prime \prime}$ latitude and between $75^{\circ} 30^{\prime} 0^{\prime \prime}$ and $78^{\circ} 30^{\prime} 0^{\prime \prime}$ longitude and it encompasses seven districts viz., Bangalore Urban, Bangalore Rural, Ramanagara Tumkur, Kolar, Chikkaballapura, Chitradurga. Total district area is $35214 \mathrm{sqkm}$ and the forest area which is focus of the study is only 9\% (Map 1.1). 


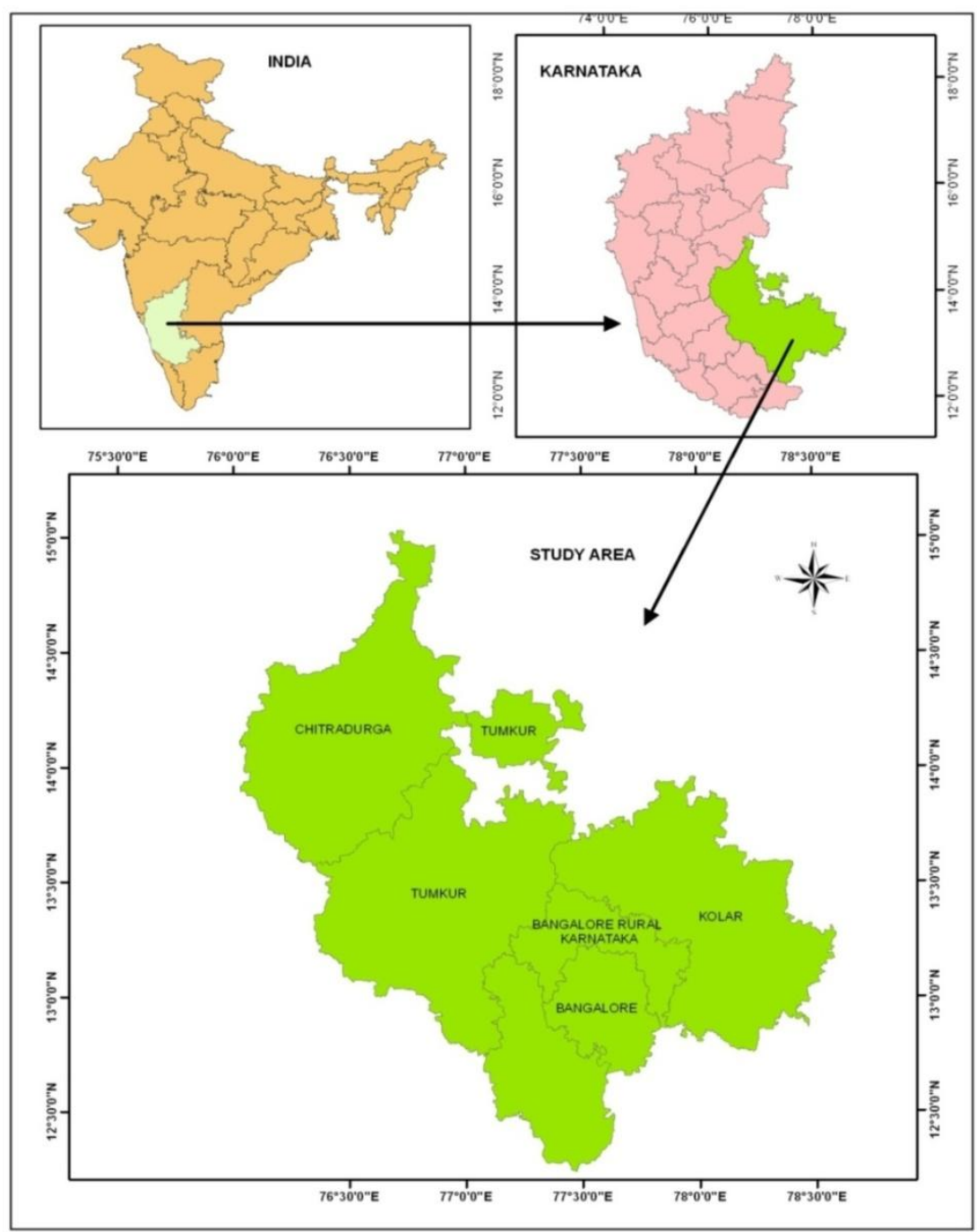

Map 1.1:- Location Map of the study area.

\section{Methodology:-}

The South-East Agroclimatic zone of Karnataka groundwater samples were colleted and 395 samples were collected from the Mines and Geology Department of Premonsoon 2014-2015. Creating different thematic maps of Hydrochemical features in the selected area using Remote Sensing and GIS Techniques. Arc GIS version 10.2.1 very useful tool to generating different thematic maps of Physico-chemical analysis of Groundwater. The sample coordinates were recorded using Global Positioning System (GPS). 


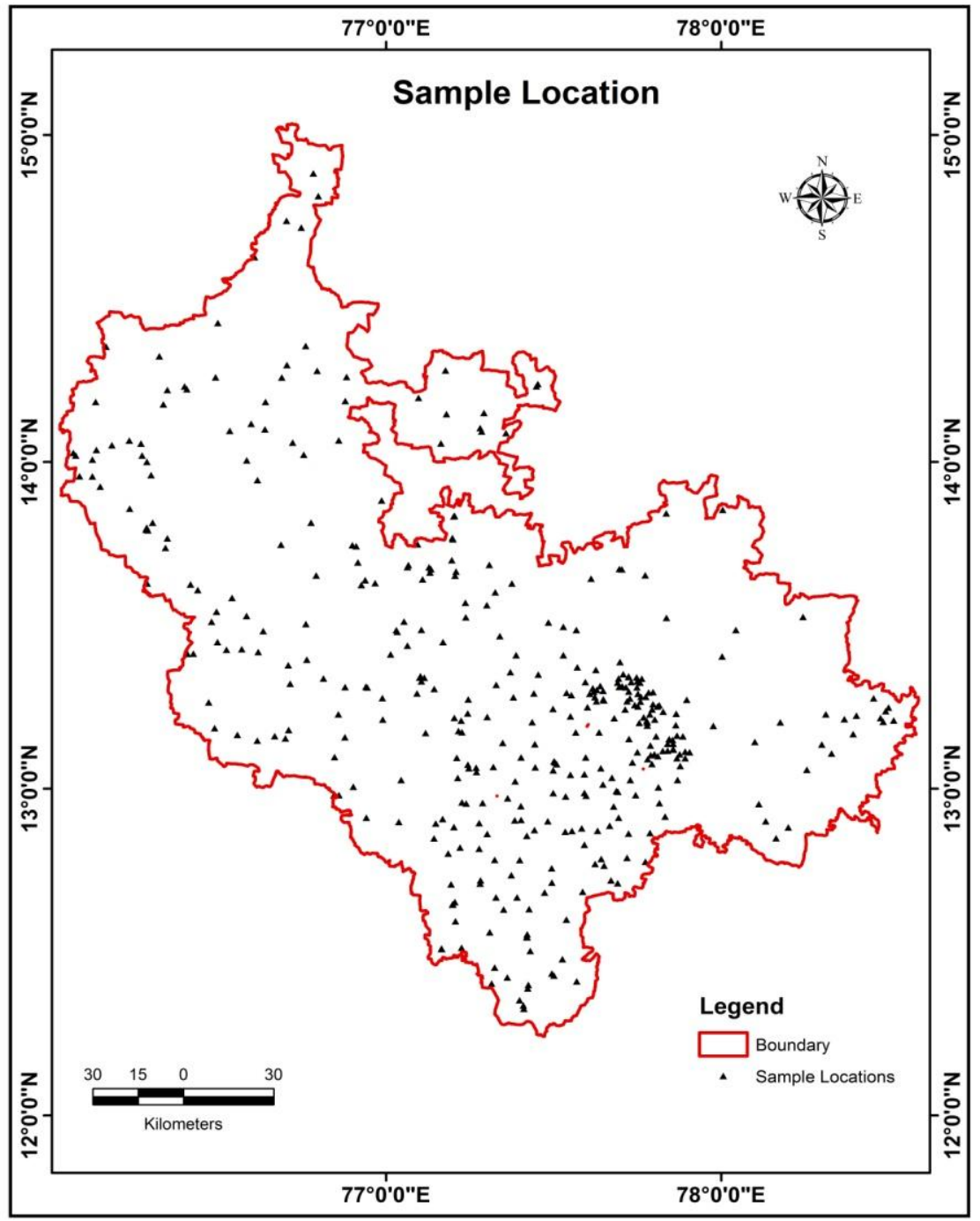

Map 1.2:- Sample Location Map. 


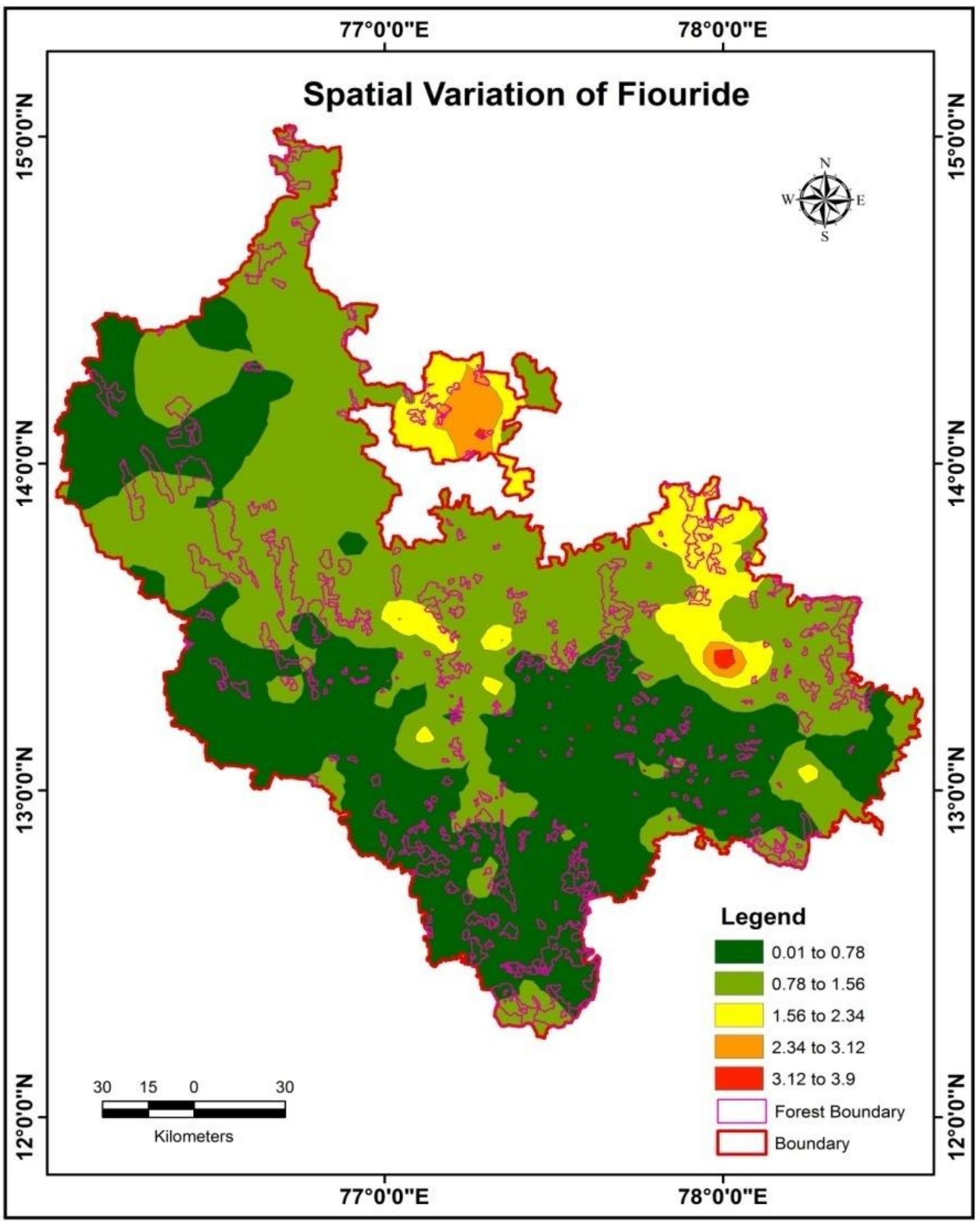

Map 1.3:- Fluoride Map.

\section{Results:-}

It is well known that small amounts of fluoride (less than $1.0 \mathrm{mg} / \mathrm{l}$ ) have proven to be beneficial in reducing tooth decay. Community water supplies commonly are treated with $\mathrm{NaF}$ or fluorosilicates to maintain fluoride levels ranging from 0.8 to $1.2 \mathrm{ppm}$ to reduce the incidence of dental carries.

Fluoride concentration for groundwater ranges between 1 to $1.5 \mathrm{ppm}$. 1 is desirable limit and $1.5 \mathrm{mg} / \mathrm{ltr}$ is permissible limit (BIS, 2009). The average value of Fluoride in the study area is $0.79 \mathrm{mg} / \mathrm{ltr}$. With a range of 0.01 to 
$3.90 \mathrm{ppm}$. Highest value showing in Northern-Eastern portion of Pavagada, Srinavasapura and Bagepalli taluks are shows high value of fluoride portion of the study area located in Chitradurga, In the forest region Fluoride ranges between Low $(0.01 \mathrm{mg} / \mathrm{ltr})$ to medium $(1.5 \mathrm{mg} / \mathrm{ltr})$ in the study area (Map 1.2).

Fluoride analysis in the selected water sample part of the forest area and surrounding forest area ranges 1 to 1.5 $\mathrm{mg} / \mathrm{ltr}$. There are five groups of classification of the study area, ranges between 0.01 to $0.78 \mathrm{mg} / \mathrm{ltr}, 0.78$ to 1.56 $\mathrm{mg} / \mathrm{ltr}, 1.56$ to $2.34 \mathrm{mg} / \mathrm{ltr}, 2.34$ to $312 \mathrm{mg} / \mathrm{ltr}$ and 3.12 to $3.9 \mathrm{mg} / \mathrm{ltr}-85$ to $90 \%$ of the study area covered under the permissible limit green color, dark color shows in the thematic maps, Medium to high in the part of Pavagada area is high fluoride concentration of study area observed Bagepalli, Sidlaghatta and chintamani area shows fluoride is increasing in hard rock terrains (Closepet Granite) areas because the fluoride improving the Pavagada, Bagepalli, Sidlaghatta area formed through hard rock terrains (Map1.3).

Low concentration of fluoride are observed in the region of Hosakote, Devanahalli, Bangalore North, Kanakapura, Channapattana, Ramanagaram, Kolar, Magadi, Turuvekere, Tipatur these are observed in the southern part of the study area. Medium concentration (0.78 to 1.56) Sira, Hiriyur, Chitradurga, Madhugiri, Gauribidhanur, Srinivasapura, Challakere and Molakalmuru area shows light green colour. High concentration shows in Pavagada, Bagepalli, Sidlaghatta and Chintamani study area and forest - area of the study area and surrounding area. In the pavagada are different types of slopes are observed normal slope, Gentle slope, Modulate slope and very gentle slope are observed in the part of Pavagada (Map 1.3).

\section{Acknowledgment:-}

Authors are thankful to the Karnataka State Remote Sensing Application Centre (KSASAC) for producing the satellite data for the study area. Author acknowledges the financial assistance under Rajiv Gandhi National Fellowship (RGNF) 2011-15.

\section{References:-}

1. Central Groundwater Board (CGWB) Ministry of Water Resources, Government of India (2010) Groundwater quality in shallow aquifers of India.

2. Choubisa SL, Choubisa L, Choubisa DK (2001) Endemic fluorosis in Rajasthan. Indian J Environ Health 43(4):177-189.

3. Reddy AGS, Rao PN (2006) Occurrence, behavior and genesis of fluoride in groundwater of Wailpalli watershed in Nalgonda District, Andhra Pradesh, India. J Appl Geochem 8(2A):618-630.

4. Subba Rao N (2003) Groundwater quality: focus on fluoride concentration in rural parts of Guntur district, AP, India. Hg Sci J 48(5):835-847.

5. Susheela AK (1999) Fluorosis management programme in India. An assessment of fluoride in the coastal aquifer of the Bara tract in Bharuch district, Gujarat, India. Curr Sci 77(10):1250-1256.

6. Vijith, H., \& Satheesh, R. (2007). Geographical Information System based assessment of spatiotemporal characteristics of groundwater quality of upland sub-watersheds of Meenachil River, parts of Western Ghats, Kottayam District, Kerala, India. Environmental Geology, 53(1), 1-9.

7. WHO (1970) Fluorides and human health. World Health Organization, Geneva.

8. WHO (2004) Guidelines for drinking water quality, 3rd edn. World Health Organization, Geneva.

9. World Health Organization (WHO) (2006) Guidelines for Drinking-water Quality. Third Edition. 1st Addendum to Vol. 1. WHO, Geneva. 